\title{
Microstructure, hardness, and wear resistance of AZ91 magnesium alloy produced by friction stir processing with air-cooling
}

\author{
Józef Iwaszko ${ }^{1} \cdot$ Krzysztof Kudła ${ }^{2}$ \\ Received: 7 January 2021 / Accepted: 11 June 2021 / Published online: 1 July 2021 \\ (C) The Author(s) 2021
}

\begin{abstract}
Friction stir processing (FSP) was used to modify the surface layer of the AZ91 magnesium alloy. The treatment was carried out using a jet cooling nozzle, generating a stream of cold air and enabling intensive cooling of the friction stir processed (FSPed) zone. Single-pass FSP was carried out using a tool rotational speed of $500 \mathrm{rpm}$ and travel speed of $30 \mathrm{~mm} / \mathrm{min}$. The treatment was conducted using a truncated cone-shaped tool with a threaded side surface. Strong grain refinement and microstructural changes typical for FSP were found in all the samples. Very fine, equiaxed recrystallized grains dominated in the stirring zone. In the samples modified with the jet cooling nozzle, greater grain refinement was obtained than in the case of naturally cooled material. The average grain size in the surface part of the stirring zone was $1.4 \mu \mathrm{m}$ and $9 \mu \mathrm{m}$ in the samples with air-cooling and with natural cooling, respectively. Both the naturally cooled specimen and air-cooled specimen were characterized by a distinctly higher hardness than the base material. The average Vickers hardness in the stirring zone was 91 HV0.1 in the FSPed sample with the air-cooling system and 85.5 HV0.1 with natural cooling, respectively. The average Vickers hardness of the as-cast alloy was 64 HV0.1. Slightly higher wear resistance of the FSPed samples using a jet cooling nozzle was found in relation to the naturally cooled sample. Based on the conducted research, high efficiency of the jet cooling nozzle in cooling the modified zone during friction stir processing was found.
\end{abstract}

Keywords Friction stir processing $\cdot$ AZ91 magnesium alloy $\cdot$ Air-cooling $\cdot$ Jet cooling nozzle $\cdot$ Microstructure evolution

\section{Introduction}

Magnesium alloys are modern engineering materials that are used in many industries. The application potential of magnesium alloys is primarily a consequence of its low specific gravity and excellent specific strength, and good machinability and recyclability. Magnesium and its alloys are the lightest metallic materials as they are lower in weight by $40 \%$

Józef Iwaszko

iwaszko@wip.pcz.pl

1 Faculty of Production Engineering and Materials Technology, Department of Materials Engineering, Czestochowa University of Technology (CUT), 19 Armii Krajowej St, 42-200 Częstochowa, Poland

2 Faculty of Mechanical Engineering and Computer Science, Department of Technology and Automation, Czestochowa University of Technology, 21 Armii Krajowej St, 42-200 Częstochowa, Poland compared to aluminum alloy and $78 \%$ to steel [1]. Unfortunately, the low hardness and resistance to abrasion and corrosion, which are typical of magnesium alloys, reduce their application potential. The microstructure and properties of magnesium alloys can be additionally shaped by means of a wide range of volumetric and surface treatments, including, e.g., technologies using concentrated heat sources such as lasers [2-5] or GTAW technology [6]. One of the latest solutions, which is becoming increasingly important in surface engineering, is the innovative friction stir processing invented by Mishra et al. [7, 8]. It is a new solid-state surface modifying technique that has been widely used for grain size refinement. FSP technology is derived from the friction stir welding (FSW) technology developed by Wayne Thomas from The Welding Institute in Cambridge [9]. Unlike FSW, FSP technology is not used to connect materials, but to shape the microstructure and properties of the surface layer. As in FSW, the heat source in FSP technology is the friction of a special non-consumable rotating tool on the surface of the modified material. During the treatment process, the rotating tool moves in the desired direction with a traverse speed and constant 
rotation. A schematic diagram of FSP is shown in Fig. 1. During FSP, a portion of plastic material flows from the advancing side (AS) to the retreating side (RS) of the rotating tool [10]. The simultaneous interaction of heat and pressure leads to dynamic recrystallization of the material in the stirring zone. The effect of friction machining is usually strong grain refinement and material homogenization. FSP is one of the most efficient methods for grain refinement, dispersion, and partial dissolution of secondary phases in the matrix, which results in enhanced mechanical and corrosion properties of the modified material [11]. FSP technology can also be used to repair cracks and voids in materials [12] or to produce composite surface layers. The reinforcing phase is introduced into the metal matrix by means of the groove method [13], the multi-chamber method [14], direct friction stir processing [15], and others. The microstructural effects in the layer modified by the FSP method depend on the main processing parameters, i.e., the speed of the working tool and the rotational speed of the tool, but also the shape and dimensions of the pin and the shoulder. Modification of the surface layer of magnesium alloys using FSP technology has been the subject of many research works and has been described in detail in the literature [16-20].

The degree of grain refinement in the material treated with FSP or FSW results primarily from the speed of cooling the modified zone; therefore, attempts are being made to retrofit devices with an additional cooling system for the material modified during processing. Simultaneous cooling of the specimen during FSP is a new approach to further improve the microstructure and properties of materials [21]. The most commonly used cooling medium is water [1, 22-25], rarely $\mathrm{CO}_{2}$ [23, 26], liquid nitrogen [1,27, 28], or compressed air $[26,29]$. To achieve accelerated cooling of the material surface layer, various constructional or methodological solutions are used. Most often it is by immersing the rotating tool and the workpiece in a cooling agent or spraying a cooling agent on the tool-workpiece interface $[10,30,31]$. It is generally

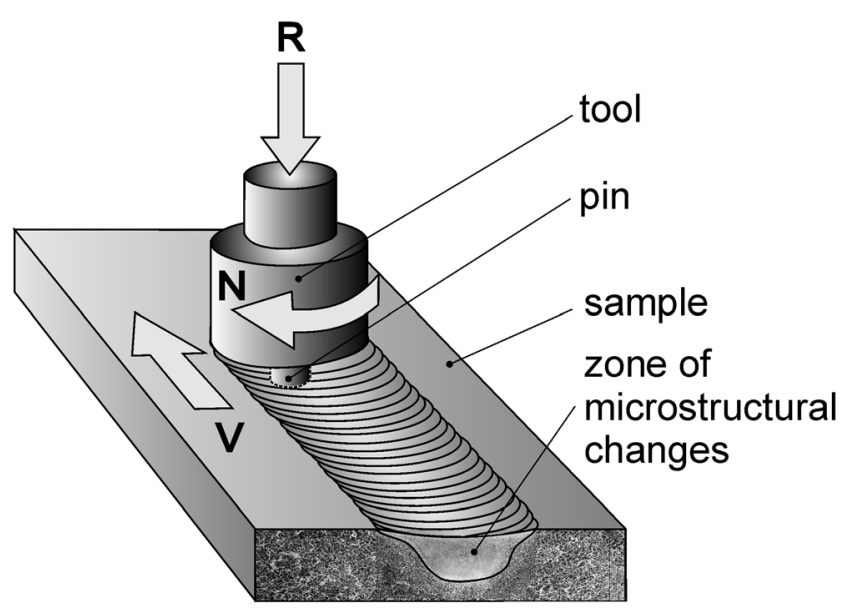

Fig. 1 Schematic illustration of FSP stated that the use of additional cooling improves the mechanical properties of modified materials as a result of very high grain refinement and homogenization of the material structure. For instance, Ramaiyan et al. [1] investigated the effect of cooling on the microstructure and properties of a friction stir processed AZ31B Mg alloy. Three different cooling methods were used, namely air, water, and cryogenic (liquid nitrogen) cooling. The authors reported that the cryogenictreated friction stir processed samples exhibit fine grain structures and hence offer better mechanical properties than the airand water-cooled processed samples. The effects of cooling during friction stir processing on the microstructure and properties of the AZ31 magnesium alloy were also investigated by Heidarpour et al. [22]. The cooling substance was water at $10^{\circ} \mathrm{C}$, which ran through grooves embedded within the copper die on which the friction stir processed specimen was placed. It was found that the cooling process during FSP led to finer and more homogenized grains because of the suppression of grain growth, and as a result, the hardness and tensile strength were improved. In turn, in [27], pre-cooling was achieved by spraying cryogenic liquid nitrogen on the FSP stand with the mounted workpiece. Liquid nitrogen was sprayed over the area to be cooled until the temperature of the setup reached the target value of $-10^{\circ} \mathrm{C}$. This resulted in the temperature at the start of the process being around $0^{\circ} \mathrm{C}$. A finer and more homogenous microstructure was observed for the pre-cooled samples when compared with the samples processed at room temperature. The authors also found that pre-cooling of the samples reduced the ductility, which improved the surface quality of these samples. Patel et al. [26] subjected the AA7075 high-strength alloy to normal and hybrid FSP with different cooling media such as compressed air, water, and $\mathrm{CO}_{2}$ to achieve different cooling rates during the process. The authors found that the microstructures of all the samples were characterized by fine equiaxed grains in the stirring zone, but the greatest elongation of the samples was achieved for the $\mathrm{CO}_{2}$-cooled sample due to the lowest heat input during FSP. In turn, in [32], friction stir processing of the AZ31B magnesium alloy was performed using an internally cooled FSP tool. The authors found that the applied solution allowed effective temperature control during processing, which leads to improvement of the mechanical properties through effective grain refinement and has a positive effect on the tool life. Ai et al. [10] used friction stir processing to modify the microstructure of the A356 cast aluminum alloy under air-cooling and water-cooling conditions. During the water-cooled FSP process, water was directly sprayed toward the processed zone behind the movement of the tool. It was found that the grains in the water-cooled sample were much smaller compared to the air-cooled FSP specimen. The authors further stated that the tensile strength and elongation are much higher for the water-cooled FSP specimen. In [28], a TIG-welded AZ31 magnesium alloy joint was subjected to two-pass rapid- 
cooling friction stir processing. It was found that two-pass rapid-cooling FSP causes significant dissolution of the coarse eutectic $\beta-\mathrm{Mg}_{17} \mathrm{Al}_{12}$ phase into the matrix and notable grain refinement in the stir zone. A good combination of ultra-high tensile strength and large elongation of the stir zone was also found.

The cited examples show that an increased cooling rate is obtained by using various apparatus and methodological solutions. Some of these methods, though, are troublesome in industrial use. For example, a major disadvantage of using water as a coolant is the need to remove it from the working area and manage it during and after treatment. Moreover, water is a corrosive agent; hence, its choice as a cooling medium in FSP treatment must be carefully considered, especially when treating materials particularly susceptible to corrosion in an aqueous environment. In turn, liquid nitrogen in contact with the material at a higher temperature evaporates very intensively, leading to the formation of a gas layer with insulating properties, which reduces the intensity of cooling. Therefore, it becomes advisable to search for such solutions that can be used in industrial conditions, without introducing significant structural and apparatus changes. As part of this work, FSP was carried out using a jet cooling nozzle. The cooling medium in this case was air-cooled to a temperature of about $-11^{\circ} \mathrm{C}$, applied with a jet cooling nozzle. There is no information in the literature on the use of a jet cooling nozzle in friction stir processing. The advantage of the solution used in this study over compressed air-cooling results mainly from the much lower air temperature generated by the jet cooling nozzle. The jet cooling nozzle makes it possible to effectively lower the air temperature even by several dozen degrees in relation to the temperature of the air flowing into the nozzle. It should be assumed that thanks to the strongly cooled air stream generated by the jet cooling nozzle, it will be possible to obtain more favorable changes in the microstructure of the material, which will then translate into an increase in hardness and/or resistance to abrasion. Are the assumptions correct and will the changes in the microstructure and properties of the magnesium alloy justify the use of a jet cooling nozzle in FSP? The authors' aim was to answer the above questions and experimentally verify the thesis. The intention of the authors of the work was also to apply and implement in FSP a cooling system offered as additional equipment for machine tools. The proposed solution is possible to be used in practice without the need for complex and expensive adaptation works or modification of the workstation. The treatment is carried out in dry conditions; hence, there is no problem with removing liquid coolant from the processing site. As part of this work, assessment of the impact of friction stir processing carried out using a jet cooling nozzle on the microstructure and properties of the AZ91 magnesium alloy was undertaken.

\section{Materials and experiment procedures}

The research material was commercially available AZ91 magnesium alloy. The chemical composition of the AZ91 Mg alloy is shown in Table 1. Cuboid samples $100 \times 80 \times 15 \mathrm{~mm}$ were made from the cast. FSP was carried out using a vertical CNC milling machine (AVIA FNE 50) enabling stepless adjustment of longitudinal $(\mathrm{X})$, transverse $(\mathrm{Y})$, and vertical $(\mathrm{Z})$ travel, as well as angular tilt of the head [33]. The CNC milling machine was equipped with a jet cooling nozzle fed with compressed air. The construction of the nozzle and its operating principles are shown in Fig. 2.

The operation of the jet cooling nozzle is based on the principle of the jet (swirl) tube. The compressed air after being fed to the jet tube is converted into two streams, i.e., a stream of cold air at one end of the tube and a stream of hot air at the other end. The source of energy in the jet tube is only compressed air; therefore, the tubes do not require an electrical power supply, which greatly simplifies their installation. The temperature obtained at the mouth of the nozzle depends on the air pressure used as well as the temperature of the air supplied to the nozzle and may be lower by up to $50^{\circ} \mathrm{C}$ in relation to the ambient temperature. The nozzle enables spot cooling and is often additional equipment for machining tools. This means that access to the technology is not limited by hardware aspects because in this case we are dealing with a design solution dedicated to use in machining tools. FSP was carried out using a tool consisting of a shoulder with a diameter of $18 \mathrm{~mm}$ and a truncated cone-shaped pin with a length of $4.9 \mathrm{~mm}$ and a diameter of $6 \mathrm{~mm}$ and $4 \mathrm{~mm}$ (the base and the top of the cone, respectively). The tool was made of X37CrMoV5-1 (H11) tool steel for hot work subjected to heat treatment (hardening and tempering). The hardness of the tool was about $51 \pm 1 \mathrm{HRC}$. The tilt angle of the tool was $2^{\circ}$. Tool travel took place after the time $t=2 \mathrm{~s}$, measured from the moment of fully penetrating the tool into the modified material. This time was necessary to plasticize the magnesium alloy. The FSP stand and used tool are shown in Fig. $3 \mathrm{a}$ and b.

Single-pass FSP was carried out using a tool rotational speed of $500 \mathrm{rpm}$ and traverse speed of $30 \mathrm{~mm} / \mathrm{min}$. The rate of penetration of the pin into the material was $6 \mathrm{~mm} / \mathrm{min}$. The air pressure supplied to the cooling nozzle was 8 bar. Highly cooled air was supplied to the friction-modified zone by means of an articulated connector terminated with an auxiliary

Table 1 Chemical composition of the AZ91 alloy

\begin{tabular}{llllllll}
\hline Alloy & \multicolumn{6}{l}{ Content of element, wt\% } \\
\cline { 2 - 8 } & $\mathrm{Al}$ & $\mathrm{Zn}$ & $\mathrm{Mn}$ & $\mathrm{Si}$ & $\mathrm{Cu}$ & $\mathrm{Fe}$ & $\mathrm{Mg}$ \\
\hline $\mathrm{AZ91}$ & 8.5 & 0.7 & 0.32 & 0.01 & 0.001 & 0.001 & Rest \\
\hline
\end{tabular}


Fig. 2 Jet cooling nozzle

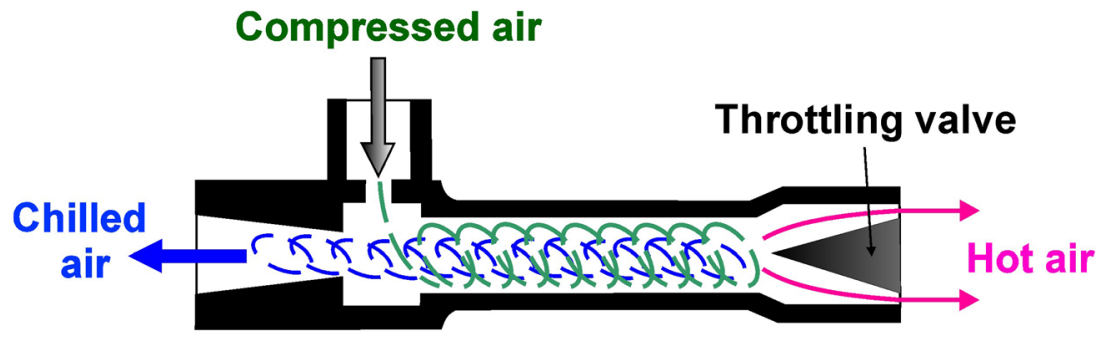

nozzle with an internal diameter of $3 \mathrm{~mm}$. The nozzle has an inclination of approximately $45^{\circ}$ in relation to the sample surface. The tip of the auxiliary nozzle supplying cooled air was about $25 \mathrm{~mm}$ from the end of the tool pin (Fig. 3c). The cooled air temperature at the outlet of the auxiliary nozzle was $-11^{\circ} \mathrm{C}$. The nozzle was integrated with the milling machine so that its position was unchanged throughout the processing. The nozzle supplying cooled air was positioned in such a way that the cold air primarily affects the already plasticized material and has the least impact on the course of the alloy plasticization process. Cooling the modified material before plasticizing may delay the plasticizing of the material and force a change in the processing parameters. Ammouri et al. [27] found that the thrust force and torque values of pre-cooled samples were $5 \%$ higher than those of room temperature samples due to material hardening induced by the cooling effect. Therefore, as part of this work, the stream of cooled air was directed at the material just behind the moving tool.

In order to evaluate the effect of friction stir processing on the microstructure and properties, metallographic specimens were prepared from a transverse cross section of the bands. The tests covered both the magnesium alloy after processing
Fig. 3 FSP stand (a), tool (b), and auxiliary nozzle setting (c) a)

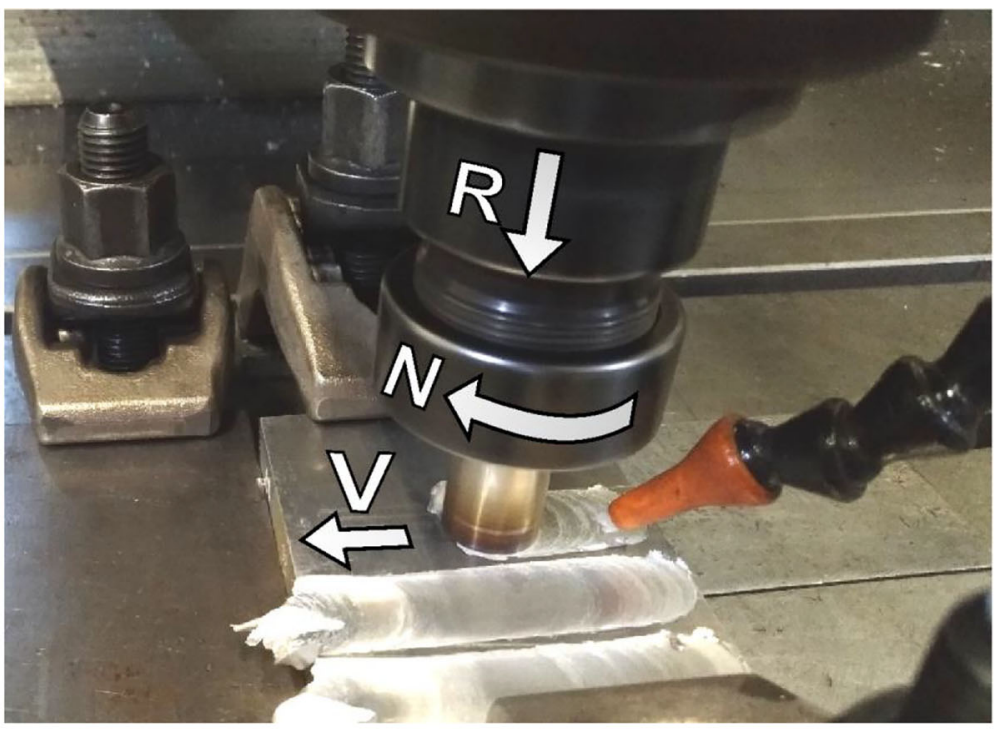

c)

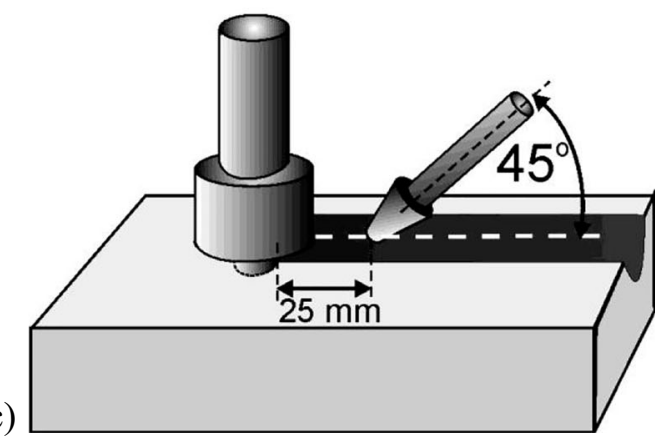


with additional air-cooling and for comparison purposes material modified without a cooling system. The obtained samples were subjected to macroscopic examination using an Olympus SZ61 stereoscopic microscope and microscopic examination using an Olympus GX41 light microscope and a JEOL JSM-6610LV scanning electron microscope. The transverse sections of the specimens were prepared by standard metallographic techniques. The specimens were grounded, polished, and etched. To determine the grain size, a measurement technique was used based on determination of the number of grains per unit area (Jeffries method). EDS tests were also carried out using an EDS Oxford Instruments X-ray microanalyzer, cooperating with a scanning electron microscope. EDX research was primarily aimed at tracing possible changes in the chemical composition of the magnesium alloy caused by processing and identifying individual structural components in the material. The material in its initial state and after friction modification was then subjected to comparative hardness measurements. The hardness measurements were conducted on cross sections of the friction stir processed zone using a Shimadzu HMV-G20 microhardness gauge with loads of $980.7 \mathrm{mN}$ applied for $10 \mathrm{~s}$. The tribological properties were measured using a T01-M pin-on-disc type laboratory tribometer under unlubricated sliding contact against a rotating steel ring (HRC 58-63). The samples were in the form of a pin with a diameter of $4 \mathrm{~mm}$ and were stationary during the tribological test. The pin was made of a material located in the central part of the band. The stand for the tribological tests is shown in Fig. 4. Prior to the tribological tests, the friction node components were degreased in ethanol. In order to eliminate the influence of the running-in process of the sample, which took place in the initial phase of the test, the samples for the tribological tests were subjected to mechanical pre-treatment. This treatment consisted in grinding the thin surface layers with abrasive paper having a gradation of 600 , to differentiate the surface roughness of individual samples. The wear tests were carried out at room temperature $\left(22^{\circ} \mathrm{C} \pm 1^{\circ} \mathrm{C}\right)$ and at the constant normal load of $30 \mathrm{~N}$. The total wear distance was $1500 \mathrm{~m}$, and the test duration was $106 \mathrm{~min}$. The linear material loss was recorded automatically against time by the tester software. The friction coefficient was calculated from the ratio of the friction force to the normal load.

\section{Results and discussion}

\subsection{Macroscopic investigations}

The macroscopic studies revealed significant changes in the geometric structure of the sample surface caused by the treatment. As a result of treatment, characteristic circular grooves were formed on the surface illustrating the way and direction of plasticized material displacement when the material was affected by the tool. Macro defects such as galling, tool dragging, or voids were not found in the frictionally modified samples. The material was solid along the entire length of the band. This fact proves that despite the intensive cooling of the material, the alloy was sufficiently plasticized to fill the space behind the travelling pin. The dimensions of the zone of microstructural changes approximated the dimensions of the

Fig. 4 Tribotester T-01M

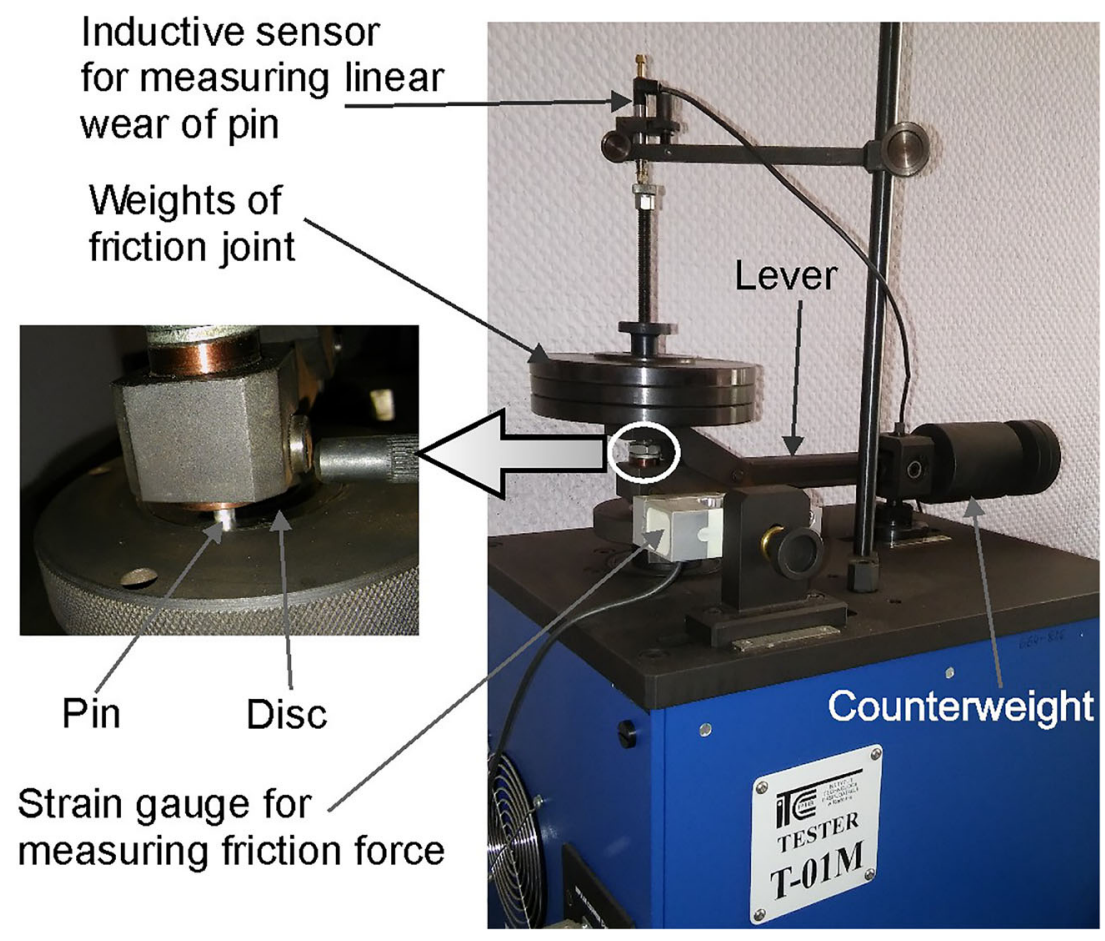


employed working tool. The band width was about $18 \mathrm{~mm}$ and was approximately equal to the diameter of the shoulder, while the depth of microstructural changes corresponded approximately to the length of the pin. The measurement of the width and depth of the zone of microstructural changes was carried out on etched transverse specimens using measuring tools provided with the microscope software. The depth was determined in the central part of the modified zone. Three independent measurements were made, and the average value was calculated. In the case of measuring the width of the friction-modified zone, the measurement was made directly at the sample surface. The depth of microstructural changes induced by the FSP treatment was analogous in both the analyzed samples, i.e., about $5 \pm 0.2 \mathrm{~mm}$; therefore, it corresponded to the tool pin length. The zone of microstructural changes is shown in Fig. 5. Ammouri et al. [27] report that in the case of pre-cooled samples, there is improvement in the surface finish in comparison to FSPed samples without pre-cooling as a result of decreased ductility of the precooled samples. Comparative analysis of the surface condition of the sample processed with a jet cooling nozzle and the naturally cooled sample, carried out as part of this work did not show, however, any noticeable differences in the geometric structure of the sample surface and the surface quality itself.

\subsection{Microstructure evolution}

\subsubsection{Microstructural investigations of AZ91 magnesium alloy in initial state}

The microstructure of the magnesium alloy in its initial state is shown in Fig. 6. The presence of large dendritic grains of the $\alpha-M g$ phase, $\alpha+\beta$ mixture, and coarse secondary eutectic $\beta$ $\mathrm{Mg}_{17} \mathrm{Al}_{12}$ phase distributed at the grain boundaries was found in the material. The grain size of the $\alpha-\mathrm{Mg}$ ranged from 30 to

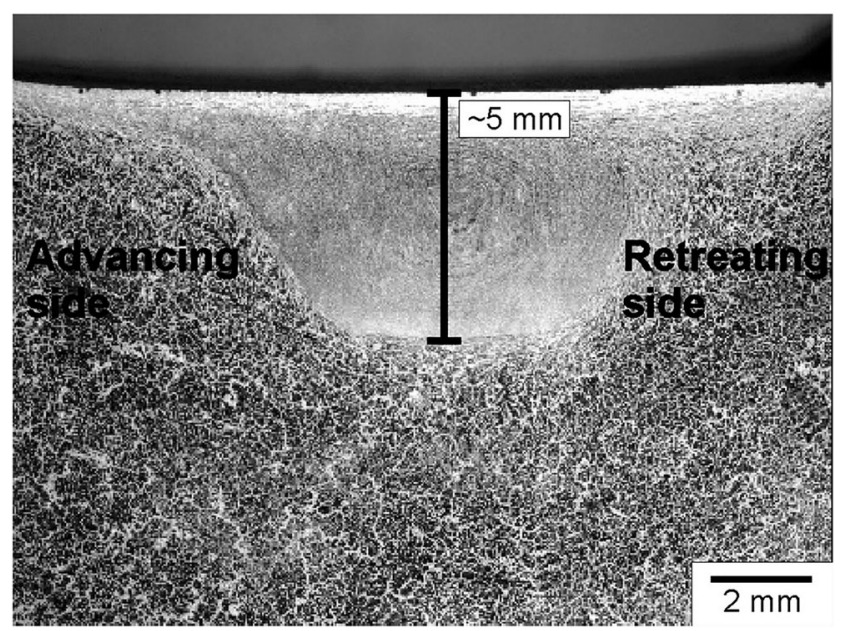

Fig. 5 Surface layer of air-cooled FSPed sample. Cross section. Etched
$200 \mu \mathrm{m}$ with an average grain size of $115 \mu \mathrm{m}$. The massive eutectic $\beta-\mathrm{Mg}_{17} \mathrm{Al}_{12}$ phase was located at the dendritic grains of the $\alpha-\mathrm{Mg}$ solid solution and formed a fine network throughout the microstructure. The individual structural components are shown in Fig. 6b. In the microstructure of the material, the presence of a few precipitates of the $\mathrm{Al}_{\mathrm{x}} \mathrm{Mn}_{\mathrm{y}}$ manganese phase was also found. These precipitates were mostly polyhedral in shape and were located in the entire volume of the material. The results of EDS analyses for the eutectic $\beta-\mathrm{Mg}_{17} \mathrm{Al}_{12}$ precipitates, $\alpha+\beta$ mixture, manganese phase, and $\alpha-\mathrm{Mg}$ solid solution are presented in Figs. 7, 8, 9, and 10. The microareas subjected to EDS analysis are marked in the figures with a white rectangle.

\subsubsection{Microstructural investigations of FSPed AZ91 magnesium alloy}

The microstructural tests of the FSPed samples revealed the presence of three characteristic zones in the surface layer of the samples, namely the stirring zone (SZ), the thermomechanically affected zone (TMAZ), and the narrow heataffected zone (HAZ) adjacent to the base material (BM). The characteristic zonal structure in the modified layer was present in all the analyzed samples, regardless of the cooling method used. In the stirring zone, the presence of grains of a more equiaxial shape in relation to the grain morphology found in TMAZ was observed. The presence of equiaxed and very fine grains in SZ should be explained first of all by the dynamic recrystallization (DRX) of the material due to the combined effect of high temperature and severe plastic deformation. Dynamic recrystallization is a predominant mechanism for grain refinement in FSPed alloys [34]. The changes in the microstructure of the alloy found during the microscopic examinations prove that the recrystallization temperature, which in the case of magnesium alloys is $0.5-0.7 \mathrm{Tm}$ (250 $400{ }^{\circ} \mathrm{C}$ ) [35], was reached during FSP. The effect of strong grain refinement in $\mathrm{SZ}$ is primarily due to dynamic recrystallization of the material, but may also be a consequence of the Zener pinning effect caused by fine $\beta-\mathrm{Mg}_{17} \mathrm{Al}_{12}$ precipitations. During FSP, the lamellar precipitations of the $\beta$ $\mathrm{Mg}_{17} \mathrm{Al}_{12}$ phase discontinuously precipitated near the eutectic $\beta-\mathrm{Mg}_{17} \mathrm{Al}_{12}$ phases that are intensely refined and located at the boundaries of the newly formed grains, effectively hinder the mobility of grain boundaries and, as a result, limit the growth of these grains thanks to the Zener pinning mechanism [36]. It is worth noting that also coarse eutectic networks can break during FSP into fine particles. Particle refinement leads to an increase in the number of grain boundaries in the material and this attribute dictates the range of the pinning effect on grain growth [37]. The recrystallization depends strongly on the size and dispersion of the particles; therefore, whether they will accelerate or hinder the recrystallization depends on their size. Coarse particles and non-dissolved particles accelerate 
Fig. 6 Magnesium

microstructure in as-cast state

Fig. 7 Result of EDS analysis of $\alpha$-Mg solid solution
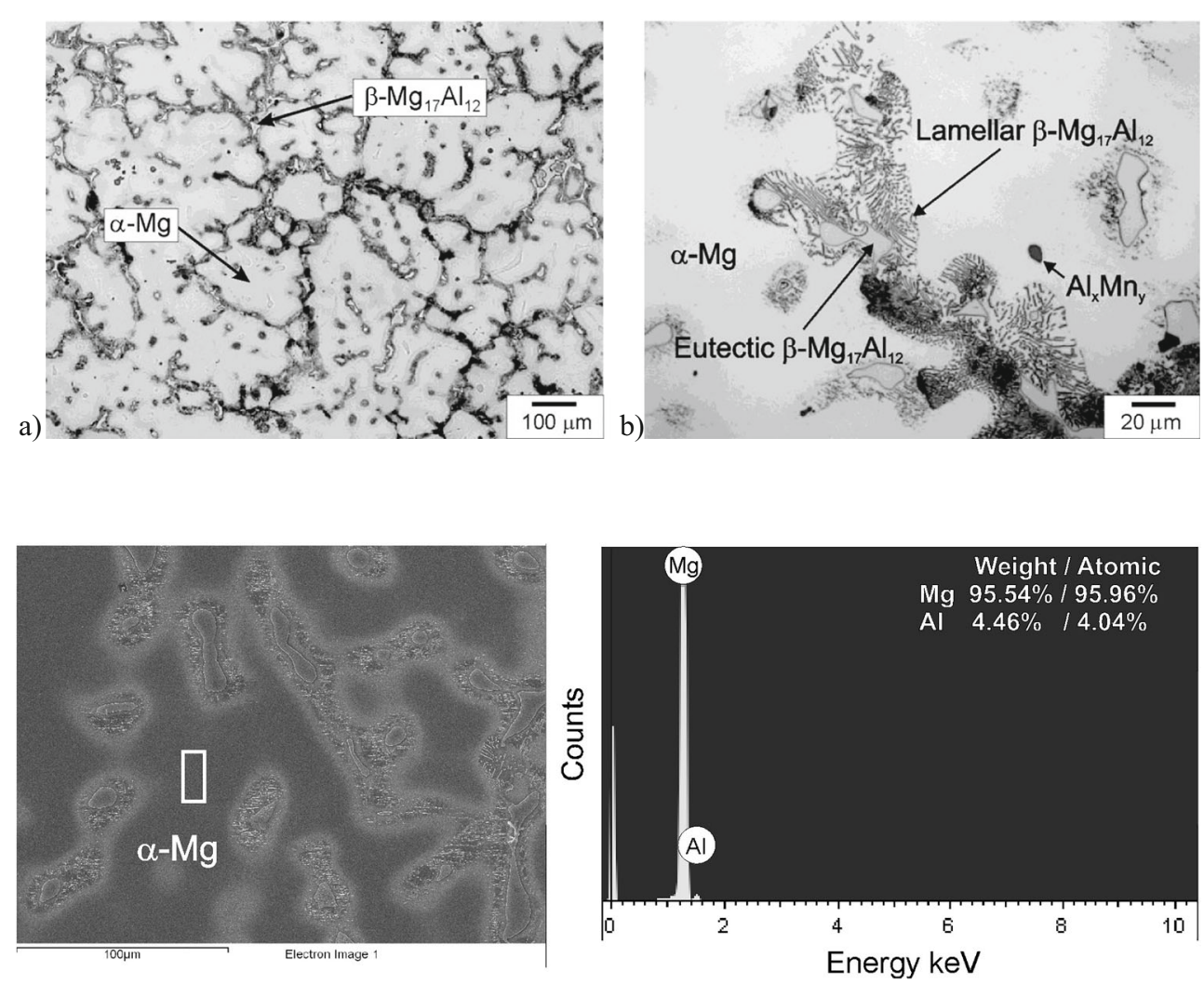

Fig. 8 Result of EDS analysis of eutectic $\beta$-phase
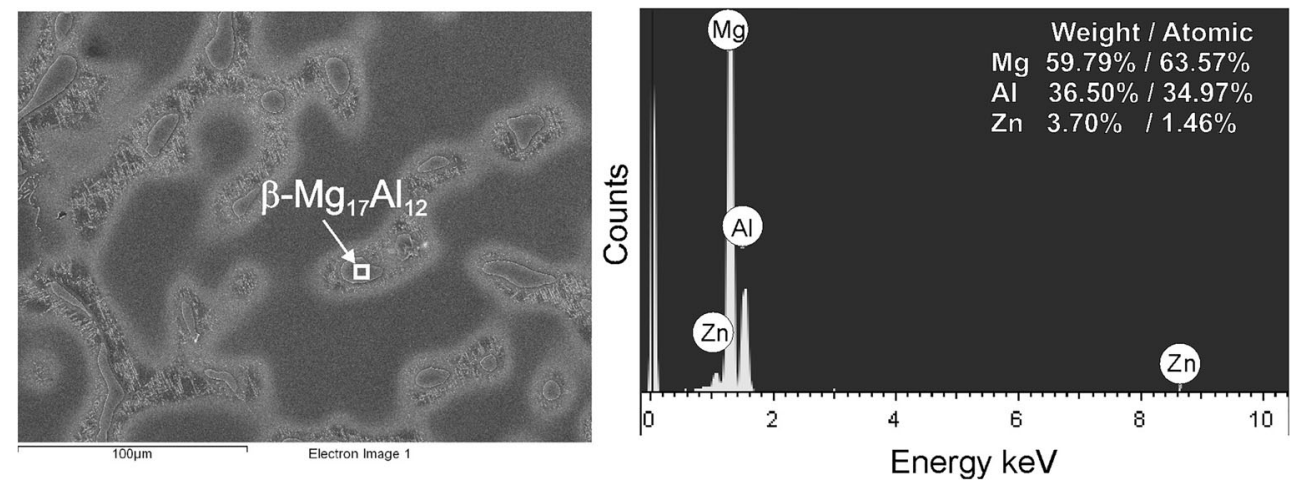

Fig. 9 Result of EDS analysis of $\alpha+\beta$ mixture
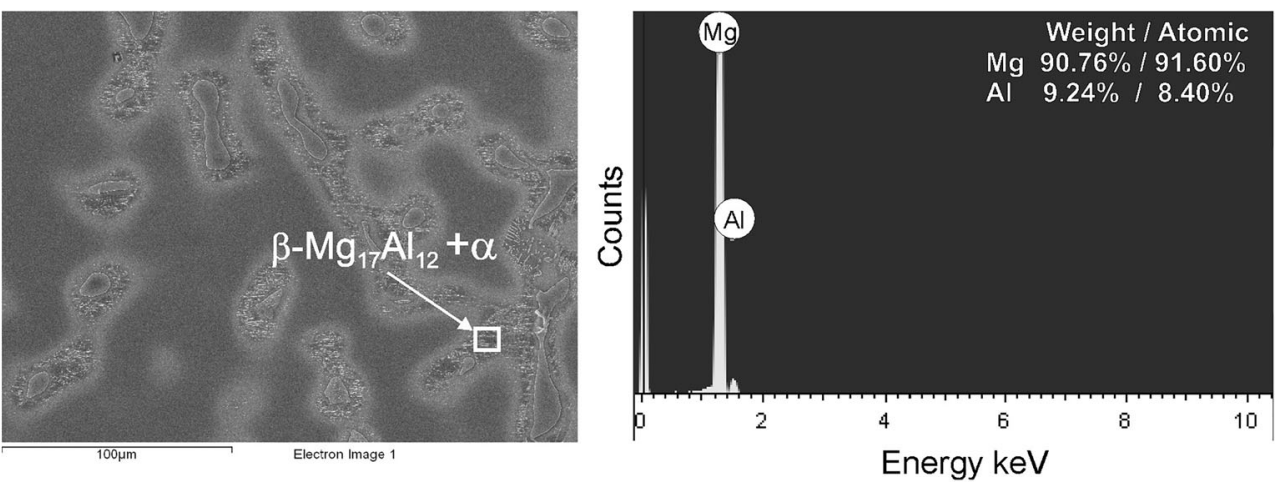
Fig. 10 Result of EDS analysis of manganese phase
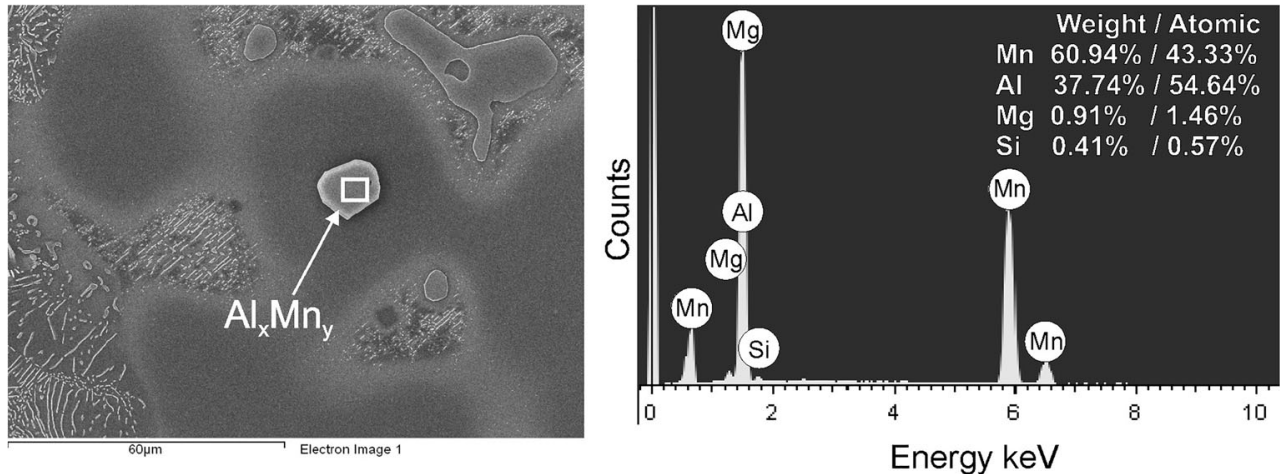

recrystallization, while fine dispersoids can hinder recrystallization as they can suppress the growth of DRXed grains during the early stage [38-40]. To sum up, the grain refinement effect obtained in AZ91 alloy after FSP is a consequence of dynamic recrystallization, but also the Zener pinning effect of the fine $\beta-\mathrm{Mg}_{17} \mathrm{Al}_{12}$ particles. Preventing the grain growth through the Zener pinning mechanism has been observed in many studies. For example, Moharami et al. [41] studied friction stir processed $\mathrm{Al}-\mathrm{Mg}_{2} \mathrm{Si}$ composites and they found that FSP plays a significant role in the refinement and dispersion of the primary and eutectic $\mathrm{Mg}_{2} \mathrm{Si}$ particles in the matrix. They reported that the micron-sized $\mathrm{Mg}_{2} \mathrm{Si}$ particles avoided the excessive mobility of grain boundaries and prevented grain growth through the Zener pinning mechanism. Moharami et al. [42] also found that the progressive decrease in the average grain sizes of the material is adjudged to be facilitated by particle-induced pinning as the FSP pass progresses.

In contrast to $\mathrm{SZ}$, the microstructure in TMAZ was affected by thermal cycling and mechanical stirring, leading to grain deformation and partial recrystallization [43]. The key issue in assessing the efficiency of the cooling system used was the grain size assessment. Measurement of the grain size in the samples treated with the jet cooling nozzle and in the modified samples without additional cooling showed that the higher cooling rate obtained as a result of using the jet cooling nozzle more effectively prevents coarsening of the grains in SZ. These results are consistent, among others, with the observations of other authors $[27,30]$. Detailed microstructural analysis of individual samples showed that the differences in grain size are particularly pronounced in the surface zone to a depth of about $1 \mathrm{~mm}$ from the surface. These differences are clearly visible in Fig. 11. The grain size in the surface layer of the alloy treated with a jet cooling nozzle was in the range of 1 to $2 \mu \mathrm{m}$, and the average value in this case was only $1.4 \mu \mathrm{m}$. In the modified sample without additional cooling, the grain size was in the range from 3 to $16 \mu \mathrm{m}$, and the average grain size was $9 \mu \mathrm{m}$; hence, it was over six times larger. What is more, in the narrow surface zone (about $50 \mu \mathrm{m}$ thick) of the naturally cooled FSPed sample, an even smaller degree of grain refinement was found as the grain size was in the range from 7 to $20 \mu \mathrm{m}$, and the average grain size was only $15 \mu \mathrm{m}$. As we moved away from the friction-modified surface, the differences in the grain size in individual samples were still noticed but were not so significant. Figure 12 shows the microstructure of the magnesium alloy occurring at a distance of about $1.2 \mathrm{~mm}$ from the surface. In the sample modified with additional cooling, the grain size was in the range from 4 to $15 \mu \mathrm{m}$ (the average grain size was about $8 \mu \mathrm{m}$ ), and in the naturally cooled FSPed sample, the grain size was in the range from 7 to $20 \mu \mathrm{m}$ (the average grain size was $12 \mu \mathrm{m}$ ). Therefore, as can be seen, the grain size in both samples increased in relation to the grain size present in the surface area, while in the case of the sample modified without additional cooling, the changes in the grain size were definitely smaller. The next figure, i.e., Fig. 13, shows examples of the microstructures present in the central part of the mixing zone, i.e., at
Fig. 11 Degree of microstructure refinement near surface. a Aircooled sample. b Naturally cooled sample
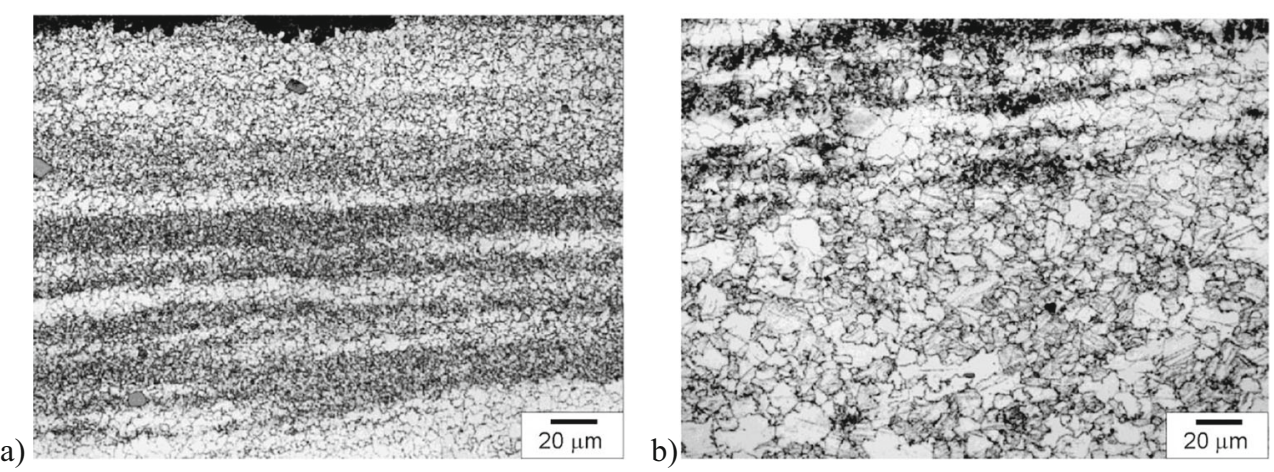
Fig. 12 Degree of microstructure refinement at distance of about $1.2 \mathrm{~mm}$ from surface. a Aircooled sample. b Naturally cooled sample
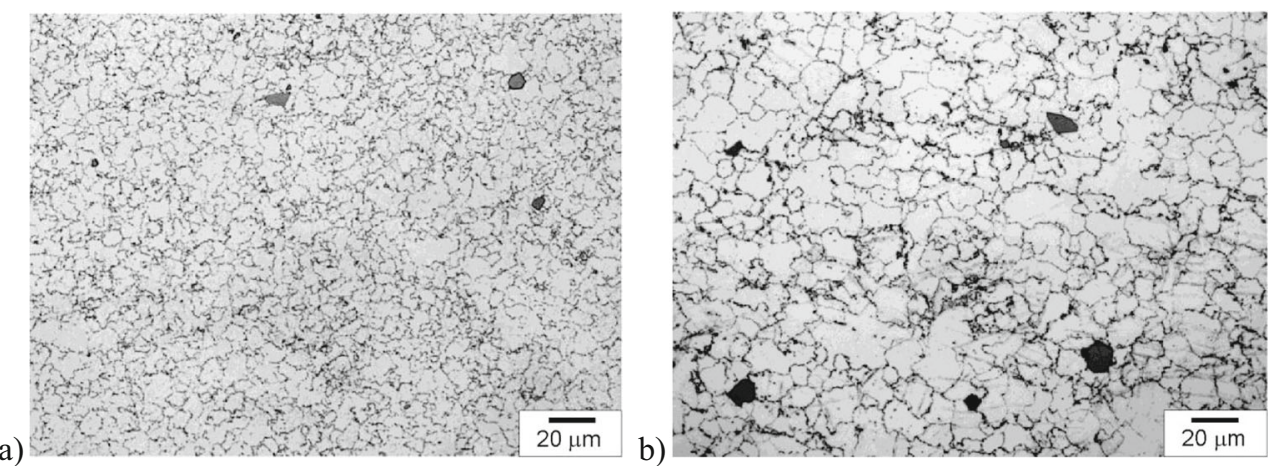

a distance of about $2.5 \mathrm{~mm}$ from the surface. Differences in the grain size between the samples cooled in different ways were still noticeable; however, these differences were much smaller than those in the case of the areas located closer to the surface. It seems obvious to combine the differences in grain size with the cooling rate of the material. Thanks to the use of the jet cooling nozzle, the cooling rate was clearly higher, which resulted in much greater grain refinement in the material, especially in the surface area. No presence of tunnels or voids in the stir zone was found in any of the samples. In all the FSPed samples, however, the presence of characteristic onion rings, consisting of concentric, elliptical rings, was found.

The surface layer of the AZ91 alloy after friction modification was subjected to EDS tests. Three microareas located at different distances from the surface, i.e., in the surface zone, in the central part of the stirring zone, and in the lower part of the stirring zone, were subjected to EDS analysis. The EDS investigation was intended to illustrate the possible differences in the chemical composition of the magnesium alloy in different places in the zone of microstructural changes. The results of EDS analysis of the sample subjected to friction modification using a jet cooling nozzle are shown in Fig. 14. No significant differences in the chemical composition of the alloy were found at different places in the stirring zone; the material was characterized by high chemical homogeneity. Similar effects were reported for the naturally cooled FSPed sample.

\subsection{Hardness measurements}

Hardness measurement is one of the basic research methods enabling very fast practical verification of the correctness of the formulated assumptions and the applied processing parameters, and tells a great deal about the nature of microstructural changes taking place in the material.

The Vickers hardness distributions across the FSPed zones are shown in Fig. 15. The average Vickers hardness in SZ was 91 HV0.1 in the FSPed sample with the air-cooling system and 85.5 HV0.1 with natural cooling, respectively. The average hardness of BM was about only $64 \mathrm{HV} 0.1$ due to its coarse dendritic structure. The hardness of the air-cooled FSPed sample was the highest in the surface zone and ranged from $90 \mathrm{HV} 0.1$ to $100 \mathrm{HV} 0.1$. At a distance of about $1 \mathrm{~mm}$ from the surface, the hardness of the material decreased and was in the range of 85-94 HV0.1. In the case of the naturally cooled FSPed samples, a lower hardness was obtained; these differences were especially visible in the case of the narrow surface zone. In this zone, the hardness of the material was in the range of $70 \mathrm{HV} 0.1$ to $87 \mathrm{HVO} 0.1$, and in the rest of the zone of microstructural changes, the hardness of the material was in the range of $80 \mathrm{HV} 0.1$ to $92 \mathrm{HV} 0.1$. The lower hardness in the surface zone noted in the case of the naturally cooled samples is undoubtedly the effect of the higher temperature to which the material was heated during processing and the longer cooling time. These factors determine the grain size after FSP. It is worth emphasizing at this point that the main source
Fig. 13 Degree of microstructure refinement at distance of about $2.5 \mathrm{~mm}$ from surface. a Aircooled sample. b Naturally cooled sample
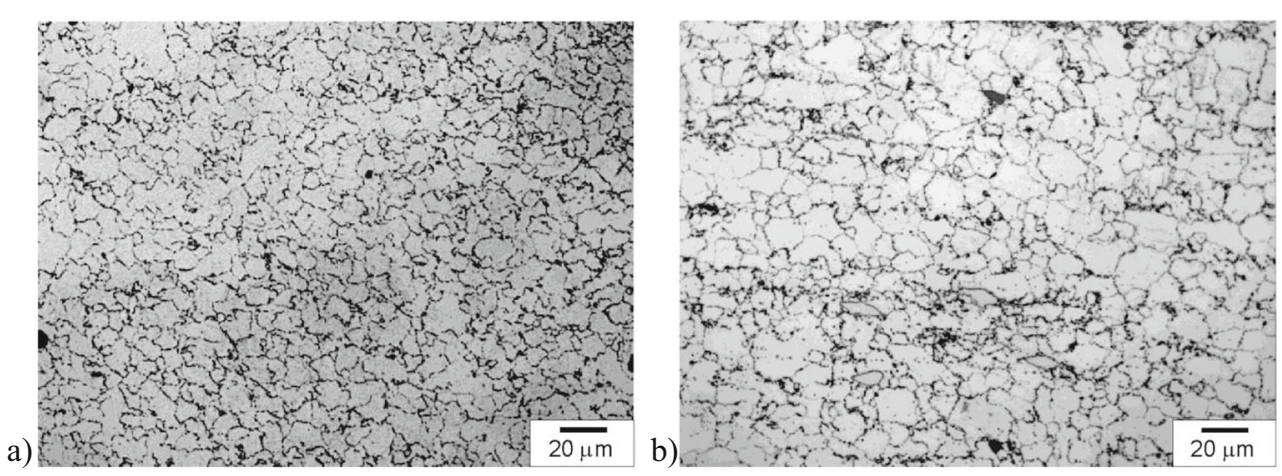


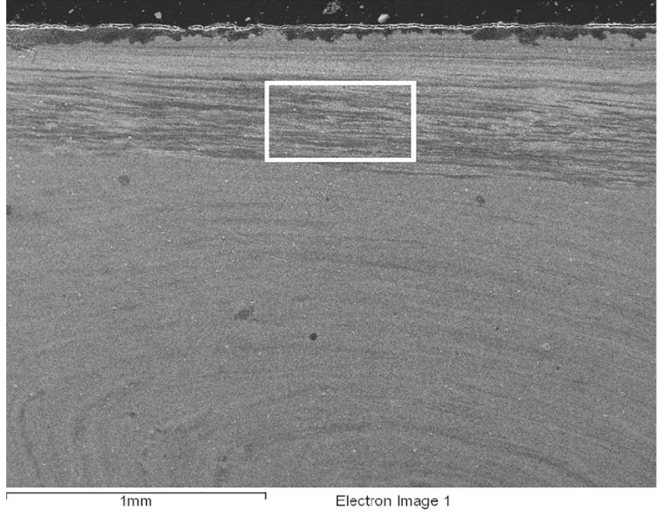

a)

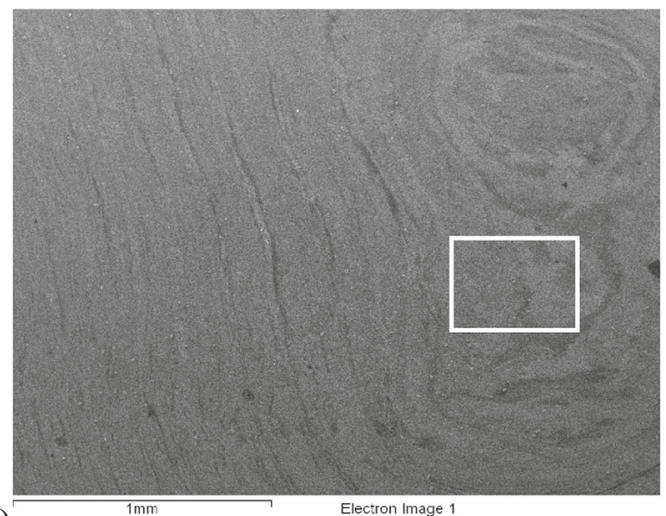

b)

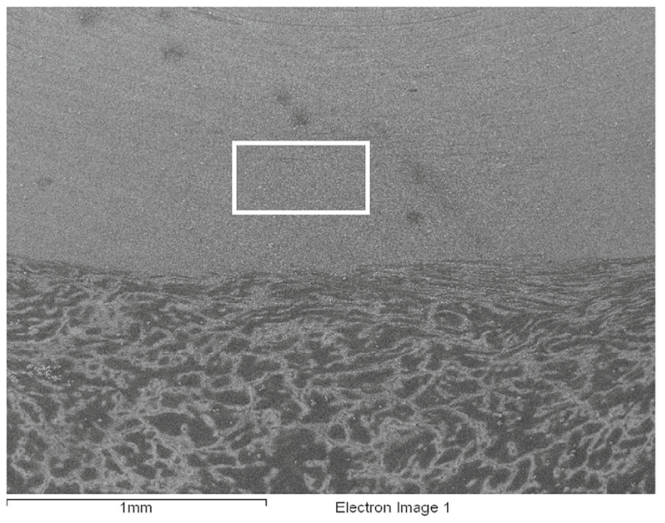

c)

Fig. 14 Results of EDS analysis. a Upper side of SZ. b Central part of SZ. c Lower part of SZ

of heat during FSP is primarily the friction of the shoulder against the surface. The authors of [44] report that even 80 to $90 \%$ of the heat generated during the friction of the tool against the surface is created as a result of friction of the shoulder. The pin has a significantly lower share in generating heat in the modified material. The use of cooling the material by means of a jet cooling nozzle means that the effect of heat on the material in the subsurface layer is significantly reduced. Based on the performed observations, it was found that the hardness of the material decreases with increasing grain size and this relationship is in agreement with the Hall-Petch
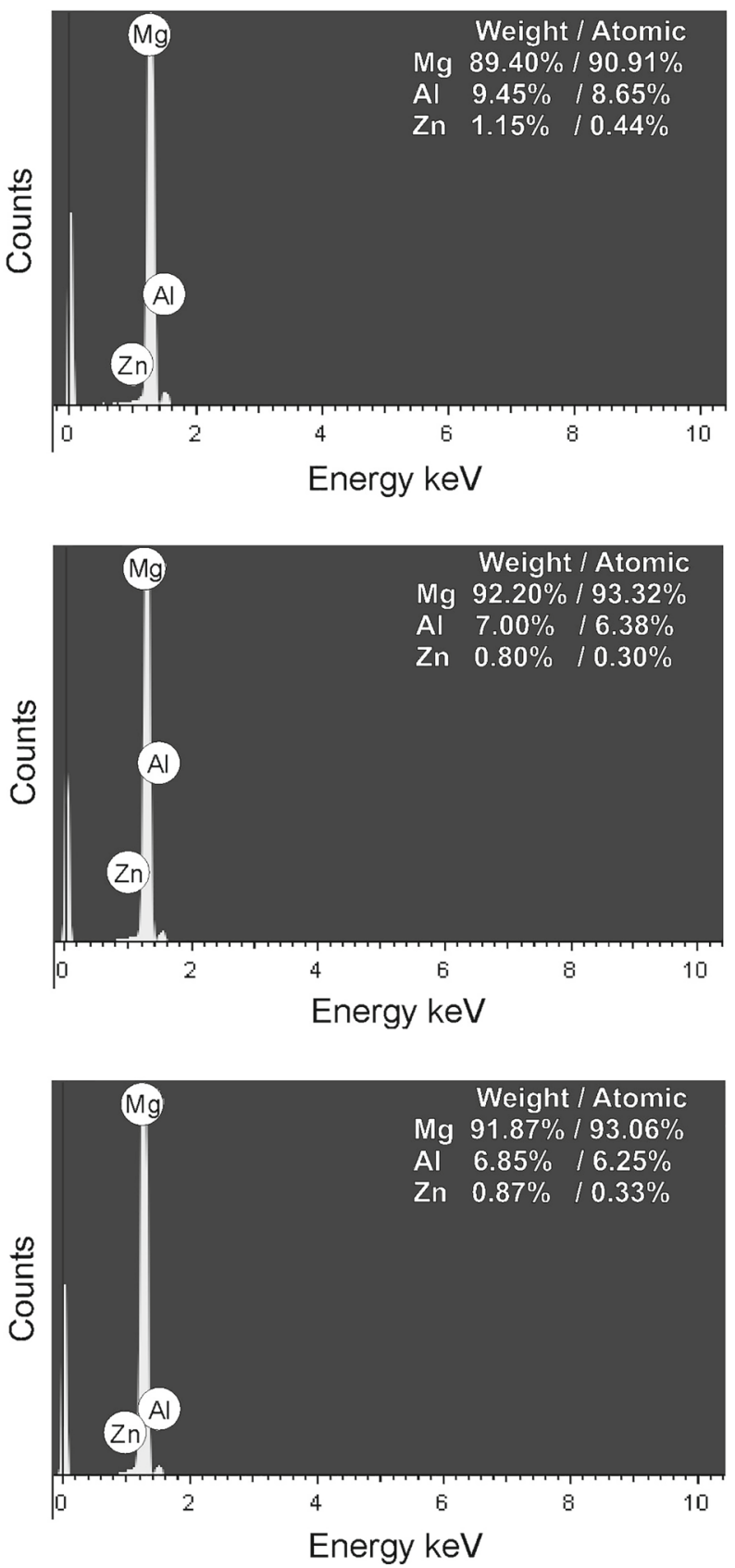

relationship. It should be assumed that the increase in hardness was a consequence, however, not only of very strong grain refinement, but also of strengthening of the solid solution as a result of dissolution of the $\beta-\mathrm{Mg}_{17} \mathrm{Al}_{12}$ phase into the magnesium matrix. Fine particles can also precipitate from the supersaturated magnesium matrix during FSP [45].

\subsection{Wear resistance tests}

Tribological tests were carried out on the material in its initial state and after FSP (Table 2). The "linear loss-test duration" 


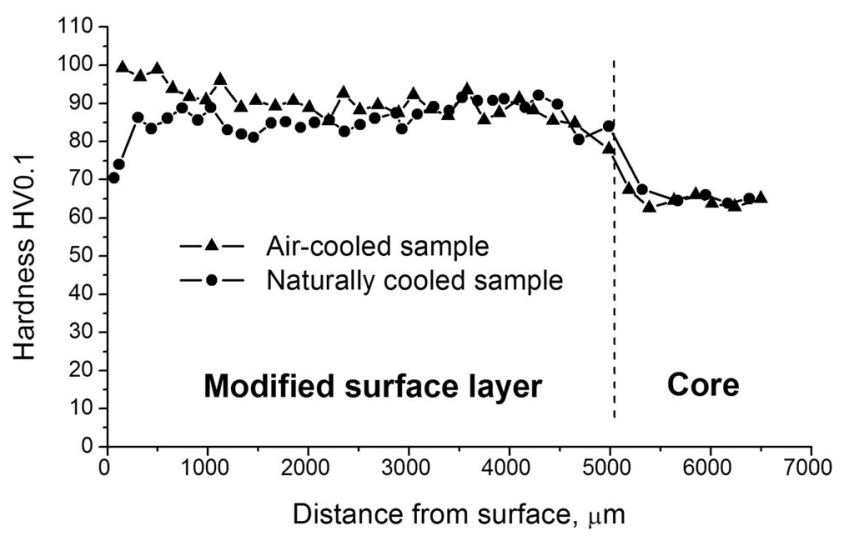

Fig. 15 Hardness measurement results

Table 2 Tribological test parameters

\begin{tabular}{ll}
\hline Load & $30 \mathrm{~N}$ \\
\hline Total sliding distance & $1500 \mathrm{~m}$ \\
Rotational speed of disk & $150 \mathrm{rpm}$ \\
Test duration & $106 \mathrm{~min}(6360 \mathrm{~s})$ \\
Pin dimensions & Diameter: $4 \mathrm{~mm}$; length: $15 \mathrm{~mm}$ \\
Disk & Diameter: $42 \mathrm{~mm}$ \\
& Type of material: bearing steel—EN \\
& 100 Cr6 (E52100 according to AISI)
\end{tabular}

characteristics prepared for the friction-modified samples and the starting material are shown in Fig. 16. In all the analyzed cases, a positive effect of FSP on the wear resistance of the magnesium alloy was noted, which was expressed by the lower linear loss of the tested sample recorded as a function of the test duration. Nevertheless, it should be noted that the improvement in the wear resistance of the naturally cooled FSPed sample or the air-cooled FSPed sample compared to the starting material was not significant. Heidarpour et al. [22] explain that the higher wear resistance of the FSPed AZ31 magnesium alloy samples than the base material is attributed to the more intense grain refinement. In contrast, Asadi et al. [30] found that there is no significant difference in the wear resistance of FSPed AZ91 magnesium alloy samples produced using different process parameters and characterized by different grain sizes.

The amounts of linear loss of material grow with an increase in the sliding time in all the tested samples. All the surfaces after FSP treatment showed lower coefficients of friction in comparison with the as-received material, though those differences were not significant. The average value of the coefficient for friction for the air-cooled FSPed samples was about 0.72 , and for the naturally cooled FSPed sample and for the as-cast magnesium alloy, it was about 0.76 and 0.78 , respectively. Figure 17 shows the graphs of the coefficient of friction as a function of the sliding time. The differences in the values of the coefficients of friction of individual samples result primarily from their different hardness because as the material hardness increases, the contact surface with the counter-sample usually decreases, which results in a reduction in the value of the coefficient of friction [46]. The hardness of the material is a consequence of the degree of grain refinement; hence, the lower coefficient of friction in the case of the FSPed samples can be attributed to the strong grain refinement. When analyzing the changes in the value of the coefficient of friction as a function of the sliding time, it can be noticed that the amplitude of changes in the value of the coefficient of friction (oscillations around the mean value) for individual samples was very similar and only in the case of the as-cast material did the mean value of the coefficient of friction increase in the initial phase test $(0-700 \mathrm{~s})$, followed by its stabilization. The increase in the value of the coefficient of friction with the sliding time/sliding distance is often explained by the hardening of the material during the test or
Fig. 16 Results of tribological tests

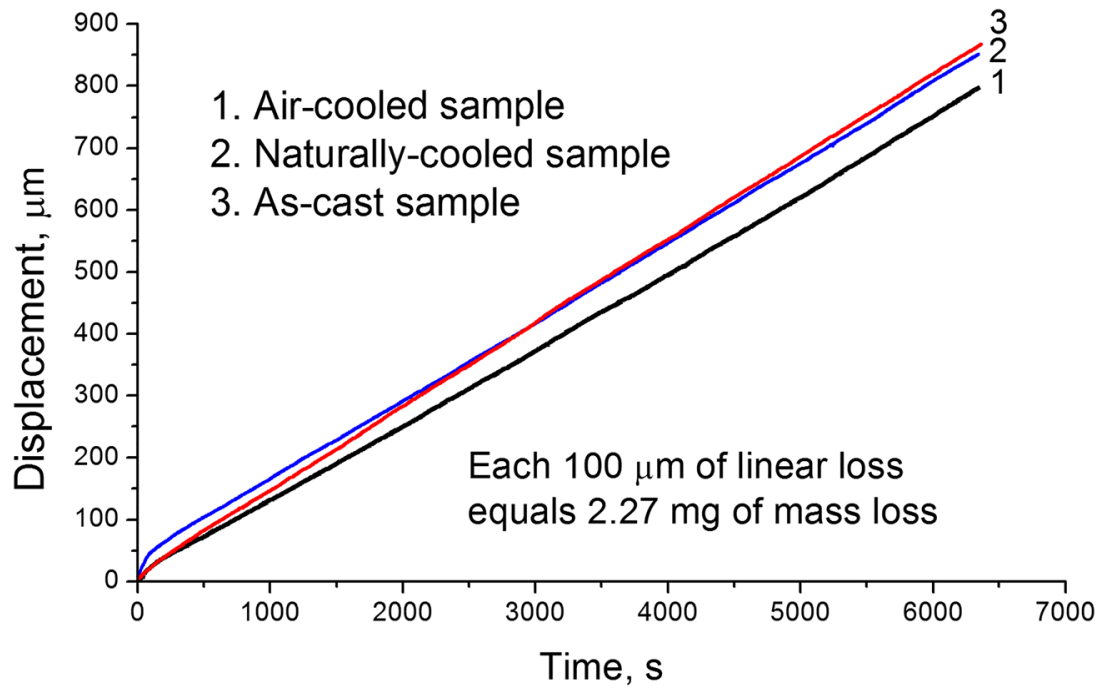


Fig. 17 Variations in coefficient of friction versus sliding time of as-cast sample (a), naturally cooled FSPed sample (b), and aircooled FSPed sample (c) under applied load of $30 \mathrm{~N}$ a)

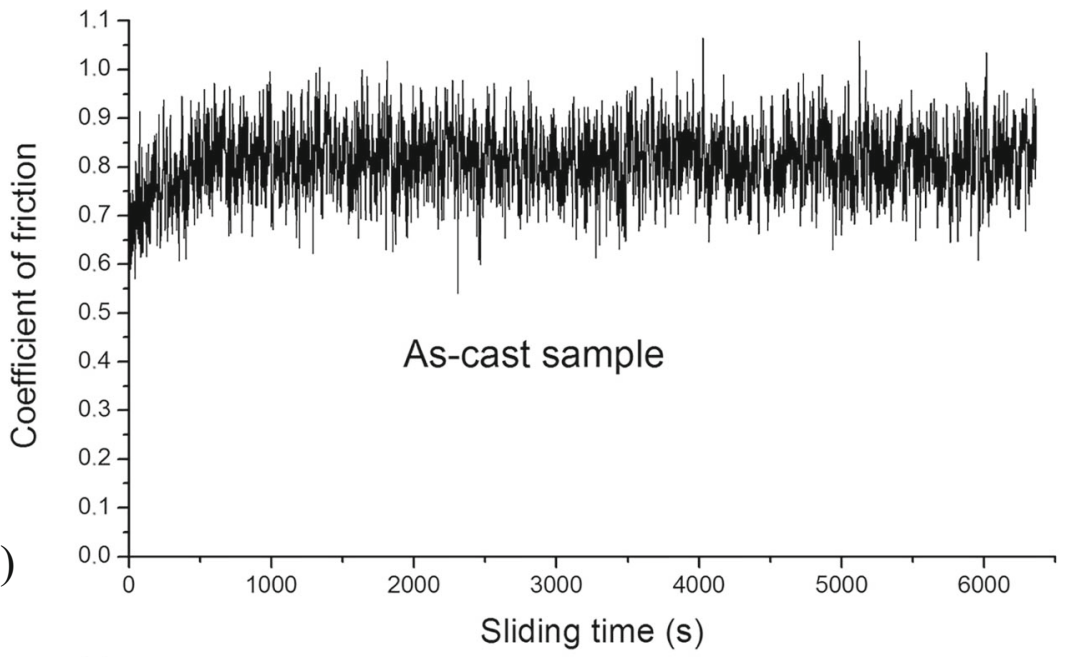

b)

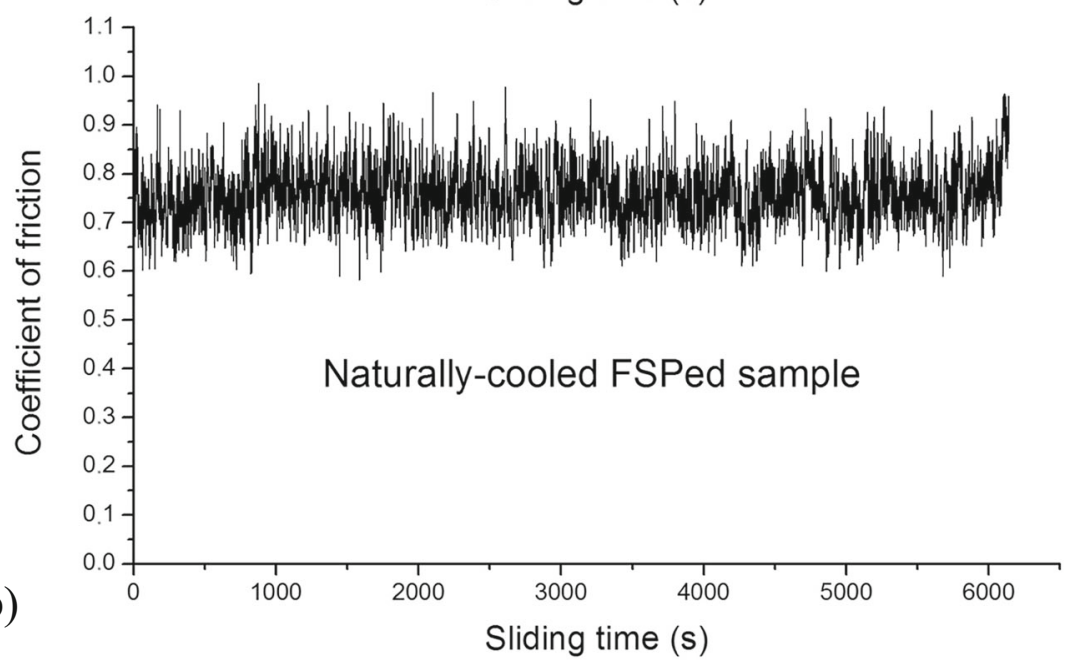

c)

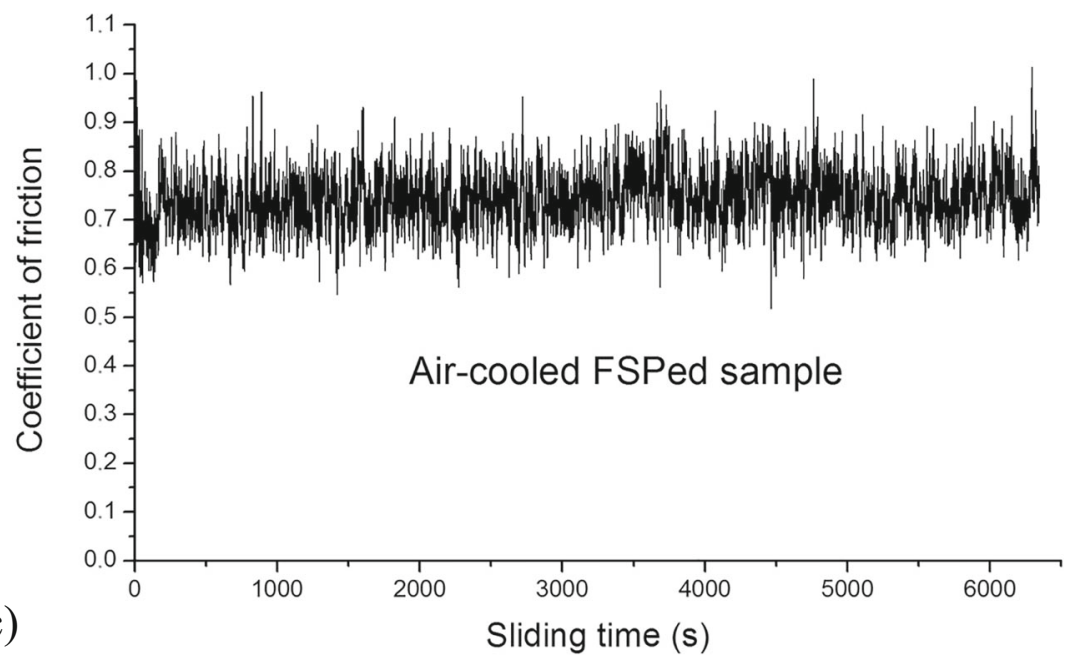

the deposition of hard contaminants [47]. In the case of the samples subjected to FSP, there was no change in the mean value of the coefficient of friction with passage of the test time; the mean value of the coefficient of friction remained constant throughout the test.
The linear material loss (displacement) for the air-cooled FSPed sample was $797 \mu \mathrm{m}$ (mass loss: $18.09 \mathrm{mg}$ ), and for the as-cast sample, it was $867 \mu \mathrm{m}$ (mass loss: $19.68 \mathrm{mg}$ ). The linear material loss (displacement) for the naturally cooled FSPed sample was $850 \mu \mathrm{m}$ (mass loss: $19.295 \mathrm{mg}$ ). The 
obtained results prove that the samples modified with the use of jet nozzle cooling are characterized by a wear intensity comparable to that of the naturally cooled samples, but it is worth noting that this wear is still lower than in the case of the naturally cooled FSPed samples.

The samples after the tribological tests were then subjected to microscopic examination to identify the wear mechanism. Figure $18 \mathrm{a}-\mathrm{d}$ show the worn surface of the samples. In all the samples, the presence of parallel and continuous grooves was found, resulting from micro-cutting and micro-plowing of the material, indicating the abrasive wear of the material. No significant metallographic differences in the geometric structure of surface can be observed between the analyzed samples. The SEM studies did not show that the wear-induced grooves were reduced or changed after FSP with air-cooling. The reasons for the formation of grooves were both unevenness on the surface of the steel counter-sample, and also the presence of wear particles in the contact region. As a rule, wear particles are strongly oxidized, which makes them harder than magnesium alloy and causes plowing or cutting of the soft surface of the magnesium alloy [48]. It worth adding that due to the strong affinity of magnesium for oxygen, the oxidation of magnesium may intensify during tribological test. As shown by the authors of [49], the worn surfaces are usually covered with a thin oxide-rich tribolayer. Since the oxidized places are more brittle than the metallic substrate, they can more easily detach from the substrate and then participate in micro-cutting and micro-plowing of the material.

\section{Conclusions}

In the present study, the cast AZ91 magnesium alloy was subjected to FSP. The material was air-cooled using a jet cooling nozzle. The effect of air-cooling on the microstructure and properties was investigated. The results of the study can be summarized as follows:

1. Friction stir processing leads to strong refinement of the AZ91 magnesium alloy grains and partial solution of the secondary precipitations of the $\beta$-phase into the magnesium matrix. The presence of very fine equiaxed grains in $\mathrm{SZ}$ is a result of dynamic recrystallization of the material.

2. FSP treatment with simultaneous sample cooling using a jet cooling nozzle has a positive effect on the microstructure and properties of the surface layer.

3. The use of a jet cooling nozzle allows a greater grain refinement to be obtained, especially in the surface area. The average grain size in the surface part of the mixing zone was $1.4 \mu \mathrm{m}$ and $9 \mu \mathrm{m}$ in the FSPed sample with the cooling system and without cooling, respectively. A

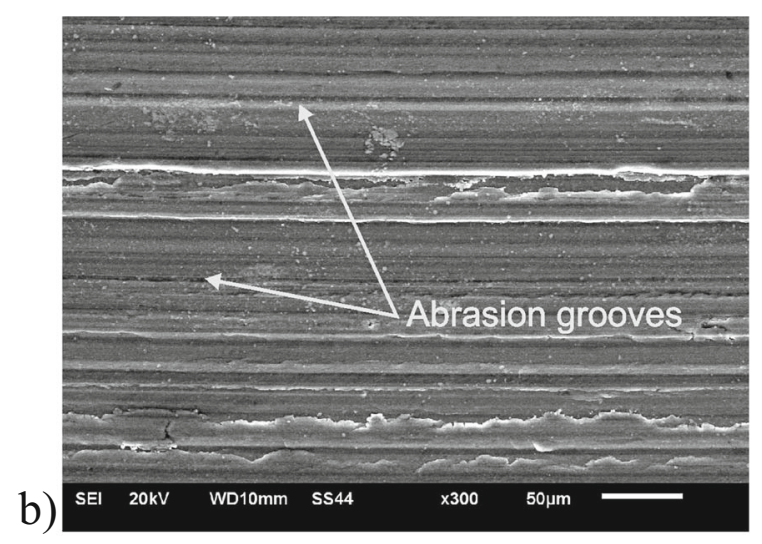

a)

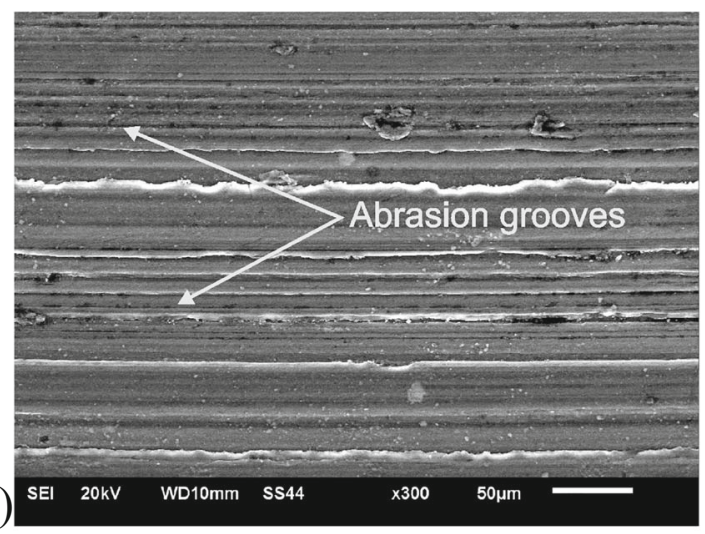

b)
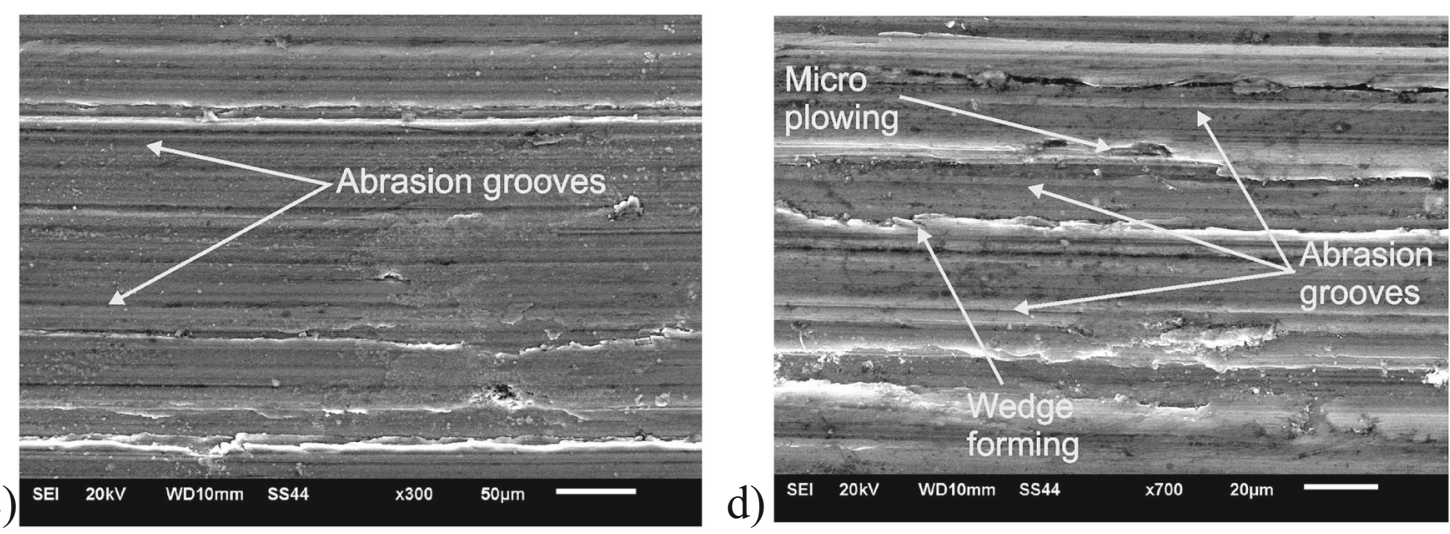

Fig. 18 Worn surface morphologies of as-cast sample (a), naturally cooled FSPed sample (b), and air-cooled FSPed sample (c, d) 
higher cooling rate effectively prevents coarsening of the grains in the stirring zone.

4. Favorable changes in the microstructure of the AZ91 alloy caused by FSP lead to a significant increase in hardness and improvement in the wear resistance of the magnesium alloy, the increase being greater in the case of the material treated with intensive cooling by means of a jet cooling nozzle.

5. Friction stir processing with simultaneous cooling of the modified material by means of a jet cooling nozzle allows elimination of the heating effect accompanying the treatment, which is particularly important in the case of multiband treatment.

6. The proposed cooling solution is possible to be used in practice without the need for complex and expensive adaptation works or modification of the workstation, and the treatment is carried out in dry conditions; hence, there is no problem with removing liquid coolant from the processing site.

7. The tests showed the high efficiency of the jet cooling nozzle in cooling the friction-modified zone. This solution can therefore be an alternative to other methods and solutions used in FSP technology and opens up new possibilities in the production of FSPed materials.

Author contribution Conceptualization, J. Iwaszko and K. Kudła; methodology, J. Iwaszko and K. Kudła; material research and writing, J. Iwaszko; review and editing, J. Iwaszko and K. Kudła; supervision, J. Iwaszko.

Funding This work was supported by the Fund for Statutory Research for Universities.

Data availability The data that support the findings of this study are available from the corresponding author, J. Iwaszko, upon reasonable request.

\section{Declarations}

Conflict of interest The authors declare no competing interests.

Open Access This article is licensed under a Creative Commons Attribution 4.0 International License, which permits use, sharing, adaptation, distribution and reproduction in any medium or format, as long as you give appropriate credit to the original author(s) and the source, provide a link to the Creative Commons licence, and indicate if changes were made. The images or other third party material in this article are included in the article's Creative Commons licence, unless indicated otherwise in a credit line to the material. If material is not included in the article's Creative Commons licence and your intended use is not permitted by statutory regulation or exceeds the permitted use, you will need to obtain permission directly from the copyright holder. To view a copy of this licence, visit http://creativecommons.org/licenses/by/4.0/.

\section{References}

1. Ramaiyan S, Chandran R, Santhanam SKV (2017) Effect of cooling conditions on mechanical and microstructural behaviours of friction stir processed AZ31B Mg alloy. Mod Mech Eng 7:144 160. https://doi.org/10.4236/mme.2017.74010

2. Li Y, Arthanari S, Guan Y (2019) Influence of laser surface melting on the properties of MB26 and AZ80 magnesium alloys. Surf Coat Tech 378:124964. https://doi.org/10.1016/j.surfcoat.2019.124964

3. Iwaszko J, Strzelecka M (2016) Effect of $\mathrm{cw}-\mathrm{CO}_{2}$ laser surface treatment on structure and properties of AZ91 magnesium alloy. Opt Laser Eng 81:63-69. https://doi.org/10.1016/j.optlaseng.2016. 01.009

4. Zeng C, Shen J, He C, Zhou M (2019) An ultrathin melted layer on magnesium alloy manufactured by low power laser. Mater Res Express 6:6. https://doi.org/10.1088/2053-1591/ab0cbe

5. Xu J, Zhou J, Tan W, Huang S, Wang S, He W (2018) Study on laser surface melting of AZ31B magnesium alloy with different ultrasonic vibration amplitude. Corros Eng Sci Tech 53(1):73-79. https://doi.org/10.1080/1478422X.2017.1398540

6. Szafarska M, Iwaszko J, Kudła K, Łęgowik I (2013) Utilisation of high-energy heat sources in magnesium alloy surface layer treatment. Arch Metall Mater 58(2):619-624. https://doi.org/10.2478/ amm-2013-0047

7. Mishra RS, Mahoney MW, McFadden SX, Mara NA, Mukherjee AK (1999) High strain rate superplasticity in a friction stir processed $7075 \mathrm{Al}$ alloy. Scr Mater 42(2):163-168. https://doi.org/10. 1016/S1359-6462(99)00329-2

8. Mishra RS, Mahoney MW (2001) Friction stir processing: a new grain refinement technique to achieve high strain rate superplasticity in commercial alloys. Mater Sci Forum. 357-359:507-514

9. Thomas WM, Nicholas ED, Needham JC, Church MG, Templesmith P, Dawes CJ (1991) Friction stir butt welding. International Patent Application No. PCT/GB92/02203, GB Patent Application No. 9125978.8

10. Ai X, Yue Y (2018) Microstructure and mechanical properties of friction stir processed A356 cast Al under air cooling and water cooling. High Temp Mater Proc 37(7):693-699. https://doi.org/ 10.1515/htmp-2017-0036

11. Vaira Vignesh R, Wang R (2018) Modelling of peak temperature during friction stir processing of magnesium alloy AZ91. IOP Conf Series: Mater Sci Eng 310:012019. https://doi.org/10.1088/1757899X/310/1/012019

12. Sajed M, Hossein Seyedkashi SM (2020) Multilayer friction stir plug welding: a novel solid-state method to repair cracks and voids in thick aluminum plates. CIRP J Manuf Sci Technol. 31:467-477. https://doi.org/10.1016/j.cirpj.2020.07.009

13. Morisada Y, Fujii H, Nagaoka T, Fukusumi M (2006) Effect of friction stir processing with $\mathrm{SiC}$ particles on microstructure and hardness of AZ31. Mater Sci Eng A 433:50-54. https://doi.org/ 10.1016/j.msea.2006.06.089

14. Iwaszko J, Kudła K, Fila K (2018) Technological aspects of friction stir processing of AlZn5.5MgCu aluminum alloy. Bull Pol Ac Tech 66(5):713-719. https://doi.org/10.24425/bpas.2018.125338

15. Huang Y, Wang T, Guo W, Wan L, Lv S (2014) Microstructure and surface mechanical property of AZ31 Mg/SiCp surface composite fabricated by direct friction stir processing. Mater Des 59:274-278. https://doi.org/10.1016/j.matdes.2014.02.067

16. Luo XC, Zhang DT, Zhang WW, Qiu C, Chen DL (2018) Tensile properties of AZ61 magnesium alloy produced by multi-pass friction stir processing: effect of sample orientation. Mater Sci Eng A 725:398-405. https://doi.org/10.1016/j.msea.2018.04.017

17. Wang W, Han P, Peng P, Zhang T, Liu Q, Yuan S-N, Huang L-Y, Yu H-L, Qiao K, Wang K-S (2020) Friction stir processing of magnesium alloys: a review. Acta Metall Sin (Engl Lett) 33:4357. https://doi.org/10.1007/s40195-019-00971-7

18. Iwaszko J, Kudła K, Fila K, Strzelecka M (2016) The effect of friction stir processing (FSP) on the microstructure and properties of AM60 magnesium alloy. Arch Metall Mater 61(3):1209-1214. https://oi.org/10.1515/amm-2016-0254 
19. Venkateswarlu G, Devaraju D, Davidson MJ, Kotiveerachari B, Tagore GRN (2013) Effect of overlapping ratio on mechanical properties and formability of friction stir processed Mg AZ31B alloy. Mater Des 45:480-486. https://doi.org/10.1016/j.matdes. 2012.08.031

20. Lan FY, Chen HM, Guo WP, Zhang J, Jin YX (2017) Effects of friction stir processing on mechanical properties and damping capacities of AZ31 magnesium alloys. IOP Conf. Series. Materials Science and Engineering 230:012013. https://doi.org/10.1088/ 1757-899X/230/1/012013

21. Singh H, Kumar P, Singh B (2016) Effect of under surface cooling on tensile strength of friction stir processed aluminium alloy 6082 . Asian J Eng Appl Tech 5(1):40-44

22. Heidarpour A, Ahmadifard S, Rohani N (2018) FSP pass number and cooling effects on the microstructure and properties of AZ31. J Adv Mater Process:47-58

23. Patel V, Badheka V, Zala S, Patel S, Patel U, Patel SN (2016) Effects of various cooling techniques on grain refinement of aluminum 7075-T651 during friction stir processing. Proceedings of the ASME 2016 International Mechanical Engineering Congress and Exposition. 14: Emerging Technologies; Materials: Genetics to Structures; Safety Engineering and Risk Analysis. Phoenix, Arizona, USA. V014T11A015. ASME. https://doi.org/10.1115/ IMECE2016-66161

24. Chai F, Zhang D, Li Y (2014) Effect of thermal history on microstructures and mechanical properties of AZ31 magnesium alloy prepared by friction stir processing. Mater 7:1573-1589. https:// doi.org/10.3390/ma7031573

25. Bocchi S, D’Urso G, Giardini C (2021) The effect of heat generated on mechanical properties of friction stir welded aluminum alloys. Int J Adv Manuf Technol. 112:1513-1528. https://doi.org/10.1007/ s00170-020-06462-9

26. Patel V, Badheka V, Li W, Akkireddy S (2019) Hybrid friction stir processing with active cooling approach to enhance superplastic behavior of AA7075 aluminum alloy. Arch Civ Mech Eng 19(4): 1368-1380. https://doi.org/10.1016/j.acme.2019.08.007

27. Ammouri AH, Kridli GT, Ayoub G, Hamade RF (2014) Investigating the effect of cryogenic pre-cooling on the friction stir processing of AZ31B. Proceedings of the World Congress on Engineering.

28. Xu N, Bao Y (2016) Enhanced mechanical properties of tungsten inert gas welded AZ31 magnesium alloy joint using two-pass friction stir processing with rapid cooling. Mater Sci Eng A 655:292299. https://doi.org/10.1016/j.msea.2016.01.009

29. Akbari M, Khalkhali A, Keshavarz SME, Sarikhani E (2018) The effect of in-process cooling conditions on temperature, force, wear resistance, microstructural, and mechanical properties of friction stir processed A356. J Mater Des Appl 232(5):429-437. https://doi.org/ $10.1177 / 1464420716630569$

30. Asadi P, Besharati Givi MK, Parvin N, Araei A, Taherishargh M, Tutunchilar S (2012) On the role of cooling and tool rotational direction on microstructure and mechanical properties of friction stir processed AZ91. Int J Adv Manuf Technol 63:987-997. https://doi.org/10.1007/s00170-012-3971-0

31. Feng X, Liu H, Babu S (2011) Effect of grain size refinement and precipitation reactions on strengthening in friction stir processed Al-Cu alloys. Scr Mater 65:1057-1060. https://doi.org/10.1016/j. scriptamat.2011.09.009

32. Albakri AN, Mansoor B, Nassar H, Khraisheh MK (2012) Simulation of friction stir processing with internally cooled tool. Adv Mater Res 445:560-565. https://doi.org/10.4028/www. scientific.net/amr.445.560

33. https://avia.com.pl/frezarki-cnc-i-konwencjonalne/fne-50/. Accesed 3.05.2021
34. Moharami A (2020) High-temperature tribological properties of friction stir processed $\mathrm{Al}-30 \mathrm{Mg}_{2} \mathrm{Si}$ composite. Mater High Temp. 37:351-356. https://doi.org/10.1080/09603409.2020.1785792

35. Jalilvand MM, Mazaheri Y, Jahani AR (2020) Effect of FSP pass number on the tribological behavior of AZ31 magnesium alloy. J Stress Analysis 4(2):9-18. https://doi.org/10.22084/jrstan.2020. 19994.1107

36. Xu SW, Kamado S, Matsumoto N, Honma T, Kojima Y (2009) Recrystallization mechanism of as-cast AZ91 magnesium alloy during hot compressive deformation. Mater Sci Eng A 527:5260. https://doi.org/10.1016/j.msea.2009.08.062

37. Moharami A, Razaghian A, Babaei B, Ojo OO, Slapakova M (2020) Role of $\mathrm{Mg}_{2}$ Si particles on mechanical, wear, and corrosion behaviors of friction stir welding of AA6061-T6 and Al- $\mathrm{Mg}_{2} \mathrm{Si}$ composite. J Compos Mater. 54:1-23. https://doi.org/10.1177/ 0021998320925528

38. Humphreys FJ, Hatherly M (2004) Recrystallization and related annealing phenomena, 2nd ed. Elsevier 219-224.

39. Chan HM, Humphreys FJ (1984) The recrystallisation of aluminium-silicon alloys containing a bimodal particle distribution. Acta Metall. 32:235-243. https://doi.org/10.1016/0001-6160(84) 90052-X

40. Jin Z-Z, Cheng X-M, Zha M, Rong J, Zhang H, Wang J-G, Wang C, Li Z-G, Wang H-Y (2019) Effects of $\mathrm{Mg}_{17} \mathrm{Al}_{12}$ second phase particles on twinning-induced recrystallization behavior in $\mathrm{Mg}-\mathrm{Al}$ Zn alloys during gradient hot rolling. J Mater Sci Technol 35:20172026. https://doi.org/10.1016/j.jmst.2019.05.017

41. Moharami A, Razaghian A (2020) Corrosion behaviour of friction stir processed Al- $\mathrm{Mg}_{2} \mathrm{Si}$ composites. Mater Sci Technol. 36:19221929. https://doi.org/10.1080/02670836.2020.1852515

42. Moharrami A, Razaghian A, Paidar M, Slapakova M, Ojo OO, Taghiabadi R (2020) Enhancing the mechanical and tribological properties of $\mathrm{Mg}_{2}$ Si-rich aluminum alloys by multi-pass friction stir processing. Mater Chem Phys 250:123066. https://doi.org/10.1016/ j.matchemphys.2020.123066

43. Li K, Liu X, Zhao Y (2019) Research status and prospect of friction stir processing technology. Coatings 9(2):129. https://doi.org/10. 3390/coatings 9020129

44. Nandan R, Roy GG, Lienert TJ, DebRoy T (2006) Numerical modelling of 3D plastic plow and heat transfer during friction stir welding of stainless steel. Sci Technol Weld Joi 11(5):526-537. https://doi.org/10.1179/174329306X107692

45. Luo X, Cao G, Zhang W, Qiu C, Zhang D (2017) Ductility improvement of an AZ61 magnesium alloy through two-pass submerged friction stir processing. Mater 10:253. https://doi.org/10. 3390/ma10030253

46. Sun HQ, Shi Y-N, Zhang M-X (2008) Wear behaviour of AZ91D magnesium alloy with a nanocrystalline surface layer. Surf Coat Technol 202(13):2859-2864. https://doi.org/10.1016/j.surfcoat. 2007.10.025

47. Zhang YS, Han Z, Wang K, Lu K (2006) Friction and wear behaviors of nanocrystalline surface layer of pure copper. Wear 260:942948. https://doi.org/10.1016/j.wear.2005.06.010

48. Banijamali SM, Palizdar Y, Najafi S, Sheikhani A, Soltan Ali Nezhad M, Valizadeh Moghaddam P, Torkamani H (2020) Effect of Ce addition on the tribological behavior of ZK60 Mg-alloy. Met Mater Int. https://doi.org/10.1007/s12540-020-00832-4

49. Moharrami A, Razaghian A, Emamy M, Taghiabadi R (2019) Effect of tool pin profile on the microstructure and tribological properties of friction stir processed $\mathrm{Al}-20 \mathrm{wt} \% \mathrm{Mg}_{2} \mathrm{Si}$ composite. J Tribol 141(12):122202. https://doi.org/10.1115/1.4044672

Publisher's note Springer Nature remains neutral with regard to jurisdictional claims in published maps and institutional affiliations. 